\title{
Change the teaching methodologies to improve e-learning quality
}

\author{
Pham Thanh Nga, LL.M \\ Guest Lecturer, Diploma Academy of Vietnam, Vietnam \\ Email: pham.nga.hlu@gmail.com | ngapham@dav.edu.vn
}

\begin{abstract}
E-learning with many outstanding advantages in training has drastically changed the self-study process due to the ability to personalize and effectively meet the learning activities of learners. Elearning and building an e-learning environment are currently paying attention and being deployed in many universities in Vietnam with different scope and levels. Especially in the current period, when science and technology are developing, many applications of technology and technology products have been applied in the field of education, changing the way of teaching and learning activities, the practice of both lecturers and students. Big Data and Artificial Intelligence (Al) technologies have replaced people not only for manual labor but also for intellectual labor, including the teaching of teachers. Many software applications have been used to replace people in the transmission of knowledge, testing, and evaluation of training quality, especially E-learning online training programs. However, in Vietnam today, the output quality of these online training programs has not been highly appreciated compared to similar programs in the world. The cause of this situation is that the training, teaching, and learning are not effective. Therefore, in this article, I will give some analysis, evaluate the current teaching and learning methods and propose solutions to enhance the interaction and initiative in the teaching and learning process of lecturers and students to improve the quality of online training in the future.
\end{abstract}

Keywords: e-learning; teaching methodologies; lecturer; learner. 


\section{Introduction}

In recent years, with the rapid development of science and technology, online learning has been widely applied at many educational levels, gradually replacing and supporting traditional education and training methods. Especially, since the Ministry of Education issued circulars guiding the training and recognition of online training at universities, the schools have stepped up this training method in educational programs mine. In recent times, when the Covid-19 translation is raging on a global scale, the promotion of online teaching and learning programs is more applicable than ever. Elearning with many outstanding advantages in training has drastically changed the self-study process due to the ability to personalize as well as effectively meet learners' learning activities. Online learning and building an online learning environment are currently paying attention and being deployed in many universities in Vietnam with different scope and levels. However, in Vietnam today, the output quality of these online training programs has not been highly appreciated compared to similar programs in the world. The cause of this situation is that the training, teaching, and learning are not effective. The question now is how to improve the quality of online training. Many studies have shown that teaching methods and methods greatly affect the quality of this type of training. Therefore, in this article, I will give some analysis, evaluate the current teaching and learning methods and propose solutions to enhance the interaction and initiative in the teaching and learning process of Lecturers and students to improve the quality of online training in the future.

\section{Literature review}

\subsection{Overview of online training}

\subsubsection{E-learning online training concept}

\section{a. Define}

Online training (e-learning) is a training process based on information technology, in which learners using computers and other smart devices easily select learning content as courses and lessons is provided via the internet, appropriate to the individual's abilities, interests and direct interaction between the instructor and the learner as well as between the learning community, which is facilitated. ${ }^{1}$

\section{b. Characteristics}

- Based on information and communication technology on the internet and WEB technology platform ${ }^{2}$

- In essence, it is still the process of transferring knowledge from the teacher to the learner under the supervision of the management system. Therefore, it needs to adhere to the basic processes of system training and implementation. E-learning is always associated with the learning process rather

\footnotetext{
1 https://dictionary.cambridge.org/dictionary/english/e-learning

${ }^{2}$ For examples: https://www.coursera.org/; https://onlinelaw.wcl.american.edu/
} 
than the teaching process.

- E-learning facilitates learners with teachers or among learners' community to exchange information more easily, as well as providing learning content that is suitable for each individual's abilities and interests.

\subsubsection{E-learning model}

In the general, e-learning model consists of 4 components:

- Content: The content of training includes the curriculum, subject lectures; processes, mechanisms, policies, technology ... related to the teaching process. The most comprehensive component of elearning training is the curriculum. The main courses are websites, e-books or other e-learning products. The courses include many lessons in one chapter of an e-book or some pages of a website. These pages or chapters contain elements of images, sounds, videos, etc. to help learners find it easier and more interested in learning. In addition, there are courseware on this floor.

- Distribution: Distribution of the training content is conducted through electronic means. For example, documents are sent to learners by E-mail, learners study on the website or via CD-ROM multimedia, etc...

- Management: The process of learning management and training is done entirely by electronic media. For example: register online or via SMS, track the progress of learning, take tests and assessments performed via the internet.

- Cooperation: The cooperation and exchange of learners in the learning process is also through electronic media. For example, exchange discussions via email, chatting, online forums, etc.

\subsubsection{E-learning subjects}

People are considered subjects in e-learning systems. People in the e-learning system include: learners, teachers and administrators. We can imagine the work of these subjects in the e-learning system as the following diagram:

- Learners are the main subjects of e-learning, they directly participate in the courses to gain knowledge provided by the teachers. Learners participating in e-learning system must get permission from the manager. They can follow the instructor's lectures directly, study the lessons directly on the e-learning system or take lectures on learning offline. When studying a problem, if there are questions, the learner will put the question on the training system and wait for the answer of the teacher or other learners.

- Teachers in e-learning are not only people who provide knowledge to learners through learning activities, tasks, announcements ... as in traditional training but also include a team. The team makes a lecture. They are script designers, e-learning designers, lesson makers and lecturers in e-learning system. In order to create a complete e-learning lecture, it is necessary to have synchronized and smooth cooperation between the works of three experts: the script designer undertakes the designing of the lecture for each lesson, assignments or tests; e-learning material designers 
undertake the creation of multimedia materials such as audio and video. In addition, teachers also receive feedback, exchange information with learners when they encounter difficulties and monitor the entire learning process of learners on the system.

- Administrators are responsible for overall management of the entire e-learning system. They are responsible for managing both the teacher and the learner. For teachers, administrators are responsible for updating the list of lectures, creating and authorizing teachers, managing the entire program of courses; decide the duration, class schedule, timetable ... For learners, administrators have the right to grant and delete accounts, view personal information and reports about their learning process.

\subsubsection{Requirements on facilities for e-Learning training}

\section{a. Request with learners}

To participate in e-learning courses, in addition to fully equipped with necessary facilities such as computers with internet connection, documents, curriculum, etc., learners need to be able to use computers: learners must have necessary computer and network skills such as installing and using software related to lessons, being able to type, be able to connect to the internet and browse the Web, etc.

\section{b. Requirements for teachers}

Lecturers need to equip basic computer skills. The minimum example must be familiar with the file structure, with opening, copying and moving files, with keyboard and mouse functions, screen properties, Windows and Web functions. Basic knowledge of Windows and Web browsers on different types of computers will affect the performance of e-learning systems. Understand the basic functions of the internet, bandwidth and speed (issues and bandwidth). Know how to use LAN, connect to the internet by modem, and look up resources. Frequently use E-mail as it will be the most common means of communicating with learners.

\subsubsection{Forms of online training}

The deployment of e-learning is quite diverse, the simplest form of online training is providing electronic lessons on CD-ROM (CBT-Computer Based Training) for learners to learn by themselves and more complex than virtual classes organized on the internet with systematic management. Currently, e-learning has several forms of training as follows:

- Asynchronous learning: teaching and learning takes place at the same time, between teachers and learners without direct interaction with each other. Teachers prepare lessons before the course takes place, and learners have the right to decide when they want to attend a course. Asynchronous training includes the following forms: self-study on WEB / internet / intranet (Web-based training WBT - Web Based Training) ${ }^{3}$ or self-study via CD-ROM (CBT - Computer Based Training); study with

\footnotetext{
${ }^{3}$ Coursera for example
} 
cassette or video tape; Ask and answer via forum or email.

- Synchronous learning: is the learning with the direct guidance of teachers and learners participating in the study almost at the same time and exchanging information directly with each other. Learning takes place via internet/intranet, using LMS (learning management system). Teachers and learners may have distance in space. Synchronous training is reflected in the forms: learning via live television, audio and video conferences, internet telephony. This method of learning helps provide immediate feedback on the learners' learning process so that the teachers and learners make necessary adjustments.

- Virtual training: learning is organized in "virtual classes" on the Internet like regular classes and via the internet/intranet, using the learning management system (LMS). Online lessons are organized to discuss issues between learners and teachers and among learners. Learners can directly study or review lectures and do off-line exercises in the same format as taking a direct class.

- Blended Learning model: is a combination of both e-learning and traditional training to achieve the highest results. These combined training courses have some lectures that are directly taught in the lecture hall and some are taught via e-learning system to make learners feel more excited and gain many benefits more by taking advantage of all the advantages of traditional training and elearning. In some country, the lack of facilities and limited research on e-learning, the blended learning model is an option reasonable.

\subsection{Overview of online teaching methodologies}

\subsubsection{Methodology of discussion}

Discussion is a method of lecturers posing problems, situations and organizing for students to exchange, debate and find answers. In essence, the method of discussion is to use the wisdom of the collective students to search for the truth. This is one of the trends in modern teaching methods. Advantages of the discussion method are:

+ Create a vibrant learning atmosphere, everyone involved in exploration to master the lesson content.

+ The most important thing about discussion method is that students form cooperative skills in thinking and in practical actions to solve problems together. This is an extremely valuable quality of the colleagues in the community. Modern Association "learn to cooperate, live together".

Method of discussion can be done as a whole class, or as a group. In the first case, the lecturer is the person who raises issues, guides, and encourages students to exchange, debate. Then, lecturer will play role of an advisor for the parties, and is the referee in the case of suspense and draw conclusions final. Methods of discussion can be conducted in groups also.

Implementing teaching process by discussion method makes the study of students become soothing, exciting. Students compete and collaborate to help each other in learning. The matter is discussed carefully. So the knowledge is long-remembered and can be applied in practice. 


\subsubsection{Method of problem-solving teaching}

The problem-solving teaching method is a teaching method in which lecturers create problematic and contradictory situations, putting students in a psychological state to explore, from which the instructors guide and encourage students find a way to solve it.

The key of problem-solving teaching method is to collect situations of conflicts, actual conflicts, suitable with the content of lectures and majors, making students try to find solutions.

There are many types of problematic situations teachers need to exploit and use as following:

$>$ A situation that is inconsistent with common sense, contrary to previous experience

$>$ Contradictory situations between theory and reality, between realities here and there.

$>$ A conflict situation

$>$ Scenario select option

$>$ Unexpected circumstances, abnormal developments.

> Hypothetical situations, predictive situations, assumptions need to be proved.

On the basis of creating situations, lecturers lead students to answer with the following options:

- Lecturers raise contradictions, bring them to a climax and then present them to solve the problem.

- Organize students to discuss solutions and lecturers to help students confirm the results.

- Organize for students to do experiments that prove or reject the situation.

The ultimate aim of problem-solving teaching is to make the best use of the intelligence of students and the collective of students, helping them to find their own knowledge, forming flexible and creative thinking methods.

\subsubsection{Method of lecture}

Lecture is a teaching method in which teachers use words to present, describe, analyze, explain, and demonstrate ... the lesson content in detail helps students listen, understand and remember. Lecture is the oldest used method in the history of teaching at university level and is still very popular in our country and many other countries in the world.

Advantages of the lecture method:

* For lecturers, the lesson is easier to perform. It does not need any technical means, but for students to listen to the teacher to analyze, explain, prove and quickly understand complex issues, grasp. A lot of information should have been put in a lot of effort and time to explore and research to be able to collect.

* Lecturers take the initiative in implementing a large knowledge program that can teach a large class of students.

* Teaching methodology in addition to providing scientific information. It can also guide students how to think, logical reasoning, and create emotions for students.

\subsubsection{Method of using textbooks, documents and the Internet}

The method of using textbooks, learning materials and the Internet is a lecturer method that guides 
students to self-study and to master the content of lessons and subjects, to deepen and expand knowledge. Therefore, learning quality is improved.

University textbooks contain standard knowledge and skills according to the prescribed program for each subject and major. University-based learning materials including workbooks, reference books, monographs and scientific, literary and artistic materials ... support students to expand and deepen their knowledge.

The Internet is a rich, up-to-date information source that can support students' reference. If it is used for study, it will greatly contribute to improving students' understanding of science fields and real life.

The question is how to do students like reading and know how to read? It is a difficult question but can be done with the following measures:

- Introducing the types of books to read for learning, expanded reference books, deepening knowledge, entertaining books for students' age.

- Guide students how to read books, search on the Internet, skills to find information, take notes, process and use information for learning purposes.

- Assign learning tasks, require students to perform research work, set a date to have written products.

- There are many jobs that can be assigned to students such as: summarizing a book, analyzing the views of an author, collecting documents for seminars, studying literature, art, science...

All tasks assigned to students, lecturers need to monitor, urge, and check progress and products to be done. There are reviews, reviews, encouragement, students do well, and have high requirements for students about the product and schedule for them to try to implement, do not ignore cases of reading books through speakers, perfunctory or completely do nothing.

\section{Findings of the research- The situation of online training in Vietnam todays}

\subsection{Laws and regulations on e-learning in Vietnam}

Currently, Vietnam has the legal provisions for online training model governed by Law on Education dated on June 14, 2005, amended in 2009 and the Education Law 2019 issued on June 14, 2019; Law on Vocational Education 2014; Higher Education Law 2012; Circular No. 10/2017/TT-BGDĐT promulgating the Regulation on distance education at university level. The organization of elearning training must also comply with the training regulations issued by the Ministry of Education and Training. Websites providing content and online training services must comply with the Government's Decree 72/2013/ND-CP on the management, provision and use of Internet services and the above information network. The information technology system related to online training must ensure the relevant laws on information safety and security. Electronic lectures and electronic learning materials must ensure that learners can self-study easily and conveniently. In order to ensure the quality of online training results, the examination and evaluation of the end of a subject 
or a course must be organized centrally, with direct supervision of the training institution, based on the charter and decision, regulations of each school ... Basic conditions for organizing online training of training institutions include: Web-portal or online training website; Server system and Internet connection infrastructure with bandwidth to meet user needs, not to cause network congestion or overload; human resources to ensure the deployment of online training activities; Online learning management system (LMS); The content management system is compiled in the direction of selfstudy materials and is built into an electronic lecture system, packaged according to SCORM standards, ensuring the requirements of electronic learning materials by the Ministry of Education and Training. Issued in accordance with Circular 12/2016/TT-BGDĐT; Regulation on online training, online training activities are subject to inspection and examination by education management agencies, state inspection agencies, relevant specialized inspection agencies and administrations at all levels. From here, it can be seen that the online education model has been allowed by the State by regulating a series of laws and regulations, requiring only online teaching and learning in compliance with the provisions of law. There will be no violation of law.

\subsection{Current Vietnam's situation of education according to current online model}

The online education market in Vietnam is estimated to be in billions of US dollars, but there are too many barriers to this potential revolution. Currently, online training is considered as a means of support, helping the classroom teacher to convey to students the amount of information that white chalk, blackboard and other traditional teaching facilities cannot do and learn. Online is an exciting new option that is expected to dramatically accelerate the educational environment. The online university is considered a competitor of the traditional university. The question now is whether online education can completely replace traditional education in the current period. In some famous universities in the world, combining e-learning with traditional direct education in lecture halls is a quite effective solution. The awareness of the learners as well as the professional ethics of the instructors is also a matter of current attention if you want to improve the quality of training in both traditional and online ways.

The advent of the internet, online education can remove all barriers. Anyone with good knowledge and communication skills can become a teacher and anyone who needs it can go to school. Despite the high production costs, online courses have the opportunity to be highly profitable. According to a study by Global Industry Analysts, the global online education market reached more than US $\$ 100$ billion in 2016. According to The Economist, the number of people enrolled in online learning in the world in 2016 reached 60 million and the forecast was reached 70 million people this year. The US is currently the country with the most popular MOOC (Massive Online Open Courses) services. These include Coursera, edX and Udacity. More than 17 leading universities in the US and other countries offer free online courses through Coursera Online Education Company, including famous universities such as Harvard and Massachusetts. 
Online education has also been introduced to Vietnam quite early. As of 2010, there have been pioneers seeking business opportunities with this model such as Violet.vn, hocmai.vn, TOPICA ..., mostly following the e-learning model. By 2012, the Ministry of Education and Training launched a virtual university project but did not leave much mark on the market. In August 2013, GiapSchool was the first unit to open MOOC portal with many courses in different fields. About 2 years later, FPT participated in another MOOC project called FUNiX. By 2016, Vietnam has about 150 start-up projects in the field of online education. These units provide curriculum from children, university to working people. With $40 \%$ of the population connected to the internet, mostly young people, the demand for education is high. Each year, Vietnamese people spend 3-4 billion USD to send their children to study abroad. Therefore, the online education and training market is full of potential with large scale and revenue growth of over $40 \%$ per year, estimated market size of not less than 2 billion USD. Therefore, not only domestic enterprises invest, Vietnam is also an attractive destination for investors in Asia such as Japan, Korea or Singapore. Currently, there are 5 leading units in the market: Topica, FUNiX, Kyna, Tienganh123 and e-Group. In developing countries, online education is a great opportunity to accelerate education and training reforms. Thereby, improving the quality of human resources for economic growth and social development.

In Vietnam, many other technology projects, online education companies in Vietnam develop spontaneously. Therefore, in the past 3 years, although witnessing many enterprises participating in the market, only the "quantity" and "quality" factors are still missing. Digital education has online learning models, including: Video Streaming, person-to-machine interaction and person-to-person interaction. So far, the interactive online learning model between students and lecturers has been more selected. However, most programs in Vietnam still focus on exam preparation, English language training or soft skills courses. The way of doing business is the same, lack of innovation and innovation in education. There are a lot of obstacles for online courses such as distance between teachers and learners, study habits, technology infrastructure ... Domestic investment enterprises mainly come from information technology group. News and group of teachers who want to participate in the field of online training. As for foreign investors, they are inclined to bring the successful programs in the world to Vietnam, but the localization is not attractive enough, so there are many investors and providers of online training services to create a vibrant and competitive market. Currently, online courses are growing and have to look for new sources of revenue. With MOOC, lecturers no longer need to work directly with a university, but create e-books or sell lessons.

\section{Conclusion and propose solutions}

The Industrial Revolution 4.0 gives humanity the opportunity to change and develop in all areas including change in education and training. E-learning or online training is an inevitable trend during the Industrial Revolution 4.0 period. In order to improve the quality of teaching and learning in online training, it is necessary to use rationally and combine different training methods to 
enhance the interaction and initiative of teachers and students in the teaching and learning process. Since then improve the quality of online training. In the course of e-learning, students will develop self-discipline, self-activeness and self-initiative when conducting self-study activities because they decide on their own time, place and content of study. However, it is not for that reason to ignore the leading role of teachers (teaching activities). The role of teachers in the process of teaching elearning is reflected in the selection of content put on the e-learning system, arranging content in the appropriate order, orienting the way of learning for students, etc. The mainstream also shows in ensuring the interactive, regular exchange between lecturers and students through e-learning system.

To succeed in an e-learning course, teachers must not only develop new pedagogical skills but also acquire new e-learning management and deployment skills. Includes some key skills:

- Proficiency in pedagogy: According to the analysis above, the e-learning environment is a different form than the traditional classroom environment. Proficiency in pedagogy will help teachers understand the objects of study and learning content. Since then, helping teachers design the course with a reasonable structure, effective learning activities help guide learners how to learn, where to start and how ... other e-learning sciences should be consulted from colleagues or from the Internet. In addition, teachers need to be willing to invest effort and time to answer learners' questions, set up information exchange forums and support systems after completing the course. E-learning is not a perfect solution, it needs to combine both forms of e-learning and face-to-face teaching to bring high results for learners. Therefore, teachers need to be creative in planning how to use and coordinate modern technology with other teaching methods in order for the teaching process to be more effective.

- Management skills include: building up their own principles, requiring learners to follow those principles and persevering with the set rules; frequently contact for support from your organization's information and communications technology experts. 


\section{Reference}

[1] Vietnam Law on Education, 2019

[2] Vietnam Higher Education Law, 2012

[3] Circular 10/2017/TT-BGDDT of the Vietnam Ministry of Education and Training on Regulation of distance learning at university level.

[4] Hanoi National University of Education, 2017, Training material for pedagogical skills for university and college lecturers.

[5] https://en.wikipedia.org.

[6] 7 ways to improve E-learning, https://elearningindustry.com.

[7] Using E-Learning technologies to improve educational quality of language teaching, https://elearningindustry.com

[8] How to make e-learning effective and tips to increase its effectiveness, https://www.talentlms.com

[9] Online education, which model will succeed, https://www.brandsvietnam.com

[10] https://dictionary.cambridge.org/dictionary/english/e-learning 